labour problem is dominated by the need to conserve existing stocks of potatoes, as in the U.S.S.R. now, such emergency methods of propagation may be justified in practice. The trade in certified seed "potato-eyes" fostered in North America" and the sporadic, small-scale cultivation of potatoes from detached sprouts or tuber cuttings in Great Britain ${ }^{3}$ add local colour and emphasis to the vast agricultural efforts now being made in the U.S.S.R.

As regards the acceleration of seed potato sprouting (loc. cit. ${ }^{1}$ ), the mechanical removal of the protecting skin could perhaps be substituted by such treatment as oxidation with potassium permanganate, or dissolution of the outer covering with cuprammonium sulphate, followed if necessary by contact with organo-mercury compounds, effected by a conveyor belt dipper ${ }^{4}$.

145 Alexandra Road, MaUrice Copisarow. Manchester, 16.

I NATURE, 150, 456 (1942); 151, 77 (1943).

- Amer. Potato J., 14, 23 (1937).

3 Polunin, Gard. Chron., January 23 (1943).

"Wakely and Mellor, NATURE, 150, 769 (1942).

\section{Physiology of Colour Vision}

The article by E. N. Willmer in Nature of February 20 is interesting, but there is no evidence that the rods are percipient elements ; rather there is overwhelming evidence that they are nerve elements sensitizing the film round the cones with the visual purple. The displacement of the positive after-image proves conclusively that the primary stimulus in vision is liquid, the muscles of the eye having a double function, one to move the eye, and the other by pressing on the back of the eye and shifting the photochomical film in the direction in which the eye is moved. The negative after-image remains in its primary position, but the positive after-image is seen farther on in the direction in which the eye is moved. This can easily be seen with a light, or even with an area of colour on a white ground. If, for example, a red square on a white ground be looked at for as short a time as possible and then the eyes be directed at a point immediately above the square, a green negative after-image will be seen at this point and higher up a distorted positive after-image or a series of red dots on a light red ground exactly similar to the cones of the retina viewed under a high-power microscope. There is no persistence of vision in ordinary circumstances when the eye is moved, but when the hand is moved in front of the eyes a dozen or more hands will be seen.

45 Dollis Hill Avenue,

$$
\text { F. W. Edridge-Green. }
$$

London, N.W.2.

Mr. E. N. WILlmer has proposed an interesting hypothesis of colour vision ${ }^{1}$. It is not possible in the length of this letter to cover all the points that $\mathrm{Mr}$. Willmer has raised. I will limit myself to two only, namely, colour mixture and adaptation.

According to Mr. Willmer's hypothesis, the parts of the spectrum lying between the red and the violet are perceived by stimulation of the rod and the cone elements in certain fixed ratios; whereas the red end of the spectrum stimulates the cones only, the violet end of the spectrum stimulates the rods only. According to this hypothesis, it should therefore be possible to match all the colours of the spectrum in

turn by suitable mixtures of red and violet rays. Experiment demonstrates conclusively, however, that such mixtures yield crimsons and purples; so that in this case hypothesis and experiment are apparently at variance.

I should expect, from Mr. Willmer's hypothesis, that exposure of the eyes to violet rays would depress for a time the sensitivity of the rod retinal perceptors. If then, immediately after such an exposure, the eye be directed at a white surface, one would expect this to appear tinted with red for a short time, due to the temporary predominance of the cone receptors. Experiment, however, shows that the white surface is tinted not with red but with yellow ; so hypothesis and experiment apparently do not agree. On exposure of the eye to red rays, according to Mr. Willmer's hypothesis, the white surface, for similar reasons, should appear to have a violet tint. Experiment, however, shows that the tinting is greenish-blue, so that again hypothesis and experiment apparently do not agree.

If there was a dearth of theories on colour vision, Mr. Willmer's hypothesis would be acceptable even if it did not fit in with all the observed facts, because any theory is of value which acts as a stimulus for further research. But there are endless theories of colour vision, many of which, after a short life, have met with a deserved and unregretted end. I hope Mr. Willmer will clear up the apparent divergencies I have pointed out above between what seem to me to be conclusions from his theory and the experimental facts.

H. Hartridge.

Physiological Department,

St. Bartholomew's Hospital Medical School, London, E.C.1.

${ }^{1}$ NATURE, 151, 213 (1943).

\title{
Minimum Human. Requirements and the Beveridge Report
}

IT is a matter for satisfaction that Sir William Beveridge has, in his report, recognized the principle that quantitative standards based on scientific knowledge may, and should, be applied to the measure. ment of minimum human requirements in food, fuel, light and clothing. As medical knowledge advances, and as cultural demands change, any standards of this nature will be gradually modified, though there can be no doubt that those for food have now been determined with a fair degree of scientific accuracy. We would express our conviction that the food standards now proposed for Great Britain, based as they are on the scales laid down by the British Medical Association and the League of Nations Technical Commission, accord with the opinion of all accredited scientific workers in this particular field.

It is not our business to decide what shall be the actual scales of cash benefit and allowance under any system of social security. That decision rests with the people of Great Britain and with their elected representatives. But we do urge that all such scales shall, in future, be related immediately to the scien. tifically estimated needs of each type of beneficiary.

JOSEPH BaRCROFT.
StAANLEY DavidSON.

F. GOWLAND HopkINs.

HORDER.

JuLIaN HuXLEY.

J. M. Mackintosh.
Charles Martin. R. MCCarrison. Moran of Manton. B. S. Rowntree. J. C. SPENCE. W. H. WYNN. 